TM-1474

\title{
Finite Element Stress Analysis of D0 Test Beam Transporter Mainframe Assembly
}

\author{
Bob Wands \\ Fermi National Accelerator Laboratory \\ P.O. Box 500, Batavia, Illinois 60510
}

September 25, 1987 


\title{
Finite Element Stress Analysis of Do Test Beam Transporter Mainframe Assembly
}

\author{
Bob Wands
}

\section{Introduction}

The D0 test beam transporter mainframe assembly is a structural frame lying in a horizontal plane and designed to support and orient the Do test liquid argon calorimeter properly in the test beam. Azimuthal adjustment is provided by a turntable with a mean radius of 64 inches, supported on a pressurized oil bearing. Angular positioning is achieved by an hydraulic actuator attached to the turntable which places force against an arm on the calorimeter vessel, causing it to rotate. Vertical positioning is adjusted by jacks at four corners of the platform.

Preliminary design calculations were based on simplifying and conservative assumptions which rendered the problem statically determinate. The purpose of this analysis is to provide more precise information on stress and deflection by including redundancies and structural detail.

\section{Mainframe Assembly Geometry and Loading}

The mainframe assembly as analyzed is shown in Fig. 1. (Drwg. ME223041). It consists of a square frame with two parallel W21x111 I-beams on two sides, and two 12 inch deep I-beams fabricated from two inch plate along the other two sides. Also on the same sides as the 12 inch beams are smaller 12 inch I-beams fabricated from one inch plate. These smaller beams are primarily present to transmit the shear force from the four jack locations to the corners of the frame. One inch plates are welded along three sides at the corners of the platform, and serve as 
jacking points for vertical support. Additional bracing and support for the turntable is provided by diagonal beams 12 inches deep and fabricated from one inch plate.

A continuous circular ring is placed on top of the frame, and supported by the flanges of the main beams and diagonals. This ring is the stationary portion of a turntable, and contains o-ring grooves to provide a seal against the mating ring for an oil bearing.

The total weight of the test calorimeter, turntable and miscellaneous components supported by the mainframe assembly is taken as $350,000 \mathrm{lbs}$. for the purpose of this analysis. The maximum possible reaction from the hydraulic actuator which rotates the vessel is assumed to be $30,000 \mathrm{lbs}$.

\section{The Finite Element Model}

The finite element model is shown in Fig. 2. Due to symmetry, only $1 / 4$ of the platform was modeled. Plate elements were used for all components. The geometry was altered slightly by placing the circular ring such that it lay exactly over the beam flanges. This meant that the mean radius of the ring was decreased by 1.25 inches, or less than two percent. This is a minor simplification and should have a negligible effect on the results.

The 350,000 lbs total weight loading was simulated by applying an appropriate uniform pressure over the surface of the ring. The $30,000 \mathrm{lb}$. reaction from the actuator was applied as a point load at the center of the 21 inch beam. This load, which might occur anywhere in azimuth, should produce the highest stress at this location. An inherent conservatism in this loading is the fact that the $30,000 \mathrm{lb}$. reaction is internal to the mass supported on the turntable, and in fact should be subtracted from the $350,000 \mathrm{lb}$. total weight. Consideration of this effect would eliminate the symmetry of the model, however, and greatly increase the modeling effort. It was decided, therefore, to err on the side of conservatism and apply the total weight and the total actuator reaction simultaneously. 


\section{Allowable Stresses}

The platform is assumed to be constructed of A36 structural steel with a minimum specified yield strength of $S_{y}=36 \mathrm{ksi}$. The maximum allowable stress in bending as specified by the AISC Specification for the Design, Fabrication and Erection of Structural Steel for Buildings is $0.66 \mathrm{~S}_{\mathrm{y}}$ or $23.76 \mathrm{ksi}$. Because this platform will be subjected to moving loads with some acceleration effects, and because of the possibility of future use at loads other than those applied in this analysis, the maximum allowable stress in bending for the purposes of this report will be taken as $0.75(0.66) \mathrm{S}_{\mathrm{y}}$ or $17.82 \mathrm{ksi}$. The maximum allowable stress in shear will be taken as $0.75(0.4) \mathrm{S}_{\mathrm{y}}$ or $10.8 \mathrm{ksi}$, which again is a $25 \%$ reduction of the allowable stress specified by the AISC Code.

\section{Results}

The moments and shear forces at four locations in the platform were extracted from the finite element results and used in calculations with the appropriate beam section properties to calculate the bending, normal, and shear stress. The stresses as calculated directly from the program were also examined for the centerspan locations, and were in general less than the stresses calculated from forces. The primary reason for this is that the finite element model includes the stiffness contribution from the circular ring, which the simplified "hand" calculation ignores.

The bending stress calculation was made using the section properties of the W21x111 I-beam as tabulated in the AISC Steel Construction Manual. The bending stress calculation for the 12 inch fabricated beam was made using the computed section modulus (see Appendix A). In both cases, the shear stress was calculated by using an area equal to the overall beam depth times the web thickness, as specified by the AISC Code.

Table I summarizes the moment, shear and stress results. 


\section{Discussion and Conclusion}

The calculated stresses are all within the allowable stress limitations with the exception of the centerspan bending stress in the 21 inch beam. The bending stress in this beam exceeds the allowable by a factor of 1.25. A beam with a section modulus of at least 1.25 times that of the present 21 inch beam, or $1.25(249)=311.25$ in $^{3}$, is required. If the 21 inch depth is retained, the lightest adequate beam is the W21x147 beam.

This analysis has dealt with only the primary structural components of the mainframe assembly. The structure at the jacking locations and other important details have not been investigated. 
Table I. Summary of Moments, Shear Forces, and Stresses in the Do Test Beam Transporter Mainframe Assembly

\begin{tabular}{|c|c|c|c|c|}
\hline Location & $\begin{array}{l}\text { Moment } \\
\text { (in-lbs) }\end{array}$ & $\begin{array}{l}\text { Shear } \\
\text { (lbs) }\end{array}$ & $\begin{array}{l}\text { Calculated } \\
\text { Stress }\end{array}$ & $\begin{array}{l}\text { ANSYS } \\
\text { Stress }\end{array}$ \\
\hline $\begin{array}{l}\text { Centerspan of } \\
21 \text { "Beam }\end{array}$ & 5564000 & 0.0 & 22345 psi & $22068 \mathrm{psi}$ \\
\hline $\begin{array}{l}\text { Centerspan of } \\
12 " \text { Beam }\end{array}$ & 2803500 & 0.0 & $9878 \mathrm{psi}$ & $8600 \mathrm{psi}$ \\
\hline $21^{\prime \prime}$ Beam at & 2548500 & - & $10235 \mathrm{psi}$ & - \\
\hline $\begin{array}{l}\text { Junction of } 21^{\prime \prime} \\
\text { Beam/12" Beam }\end{array}$ & - & 61500 & $5325 \mathrm{psi}$ & - \\
\hline $12 "$ Beam at & 373500 & - & $1300 \mathrm{psi}$ & - \\
\hline $\begin{array}{l}\text { Junction of } 21^{\prime \prime} \\
\text { Beam/12" Beam }\end{array}$ & - & 41000 & $1426 \mathrm{psi}$ & - \\
\hline
\end{tabular}



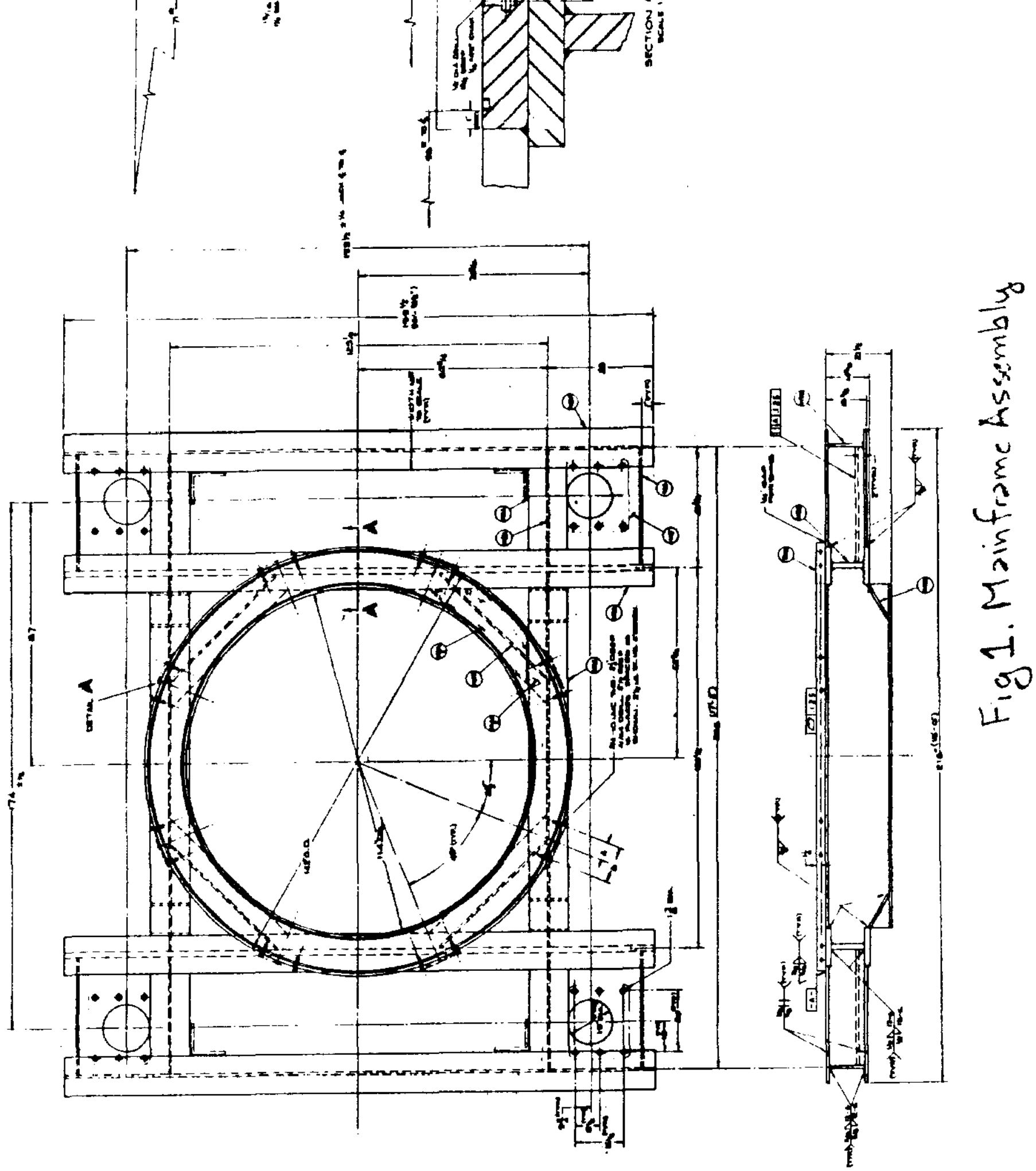


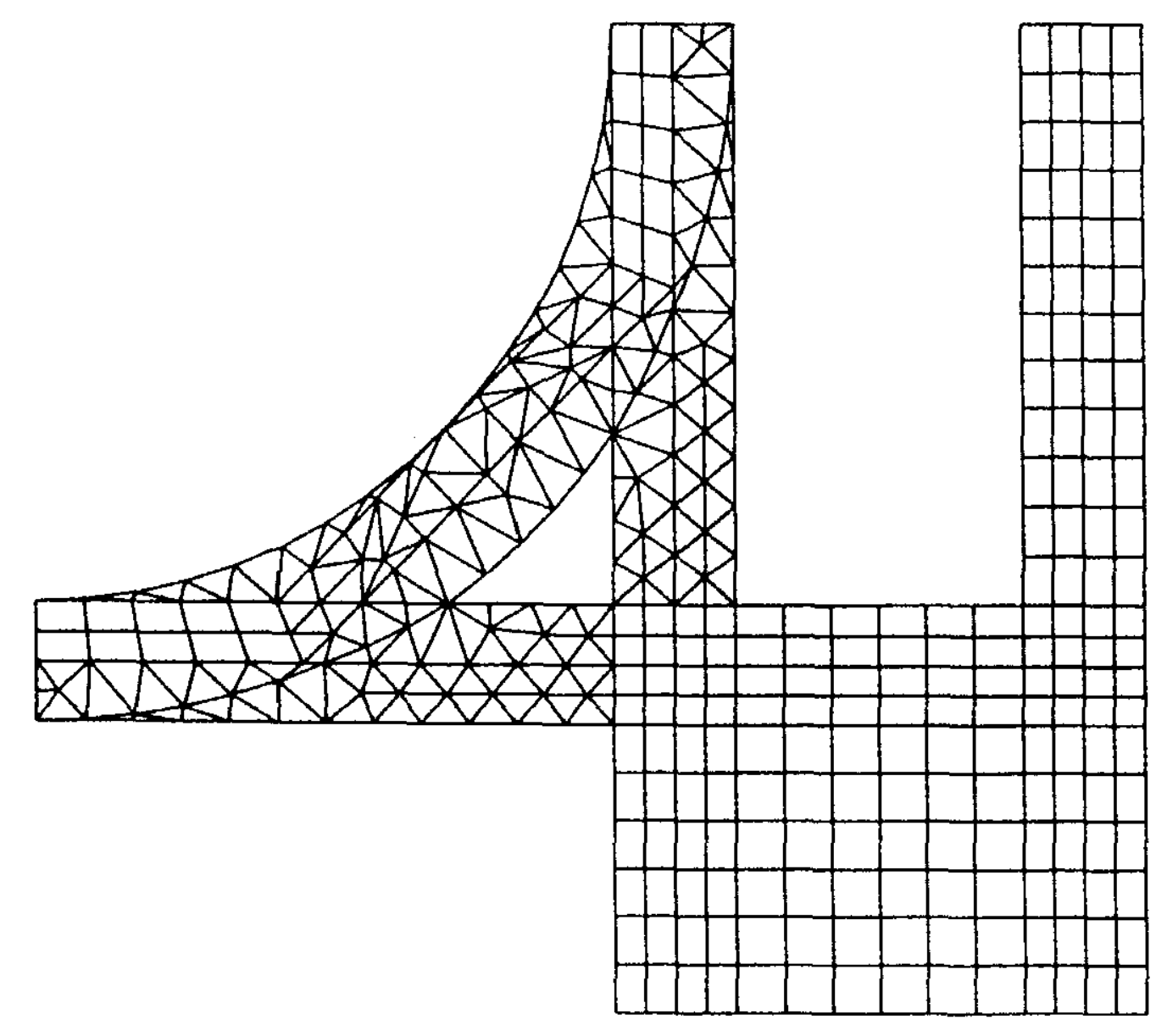

TEST LAC MODULE PLATFORM

Figh Finite Element Model
of $/ 4$ of Platform

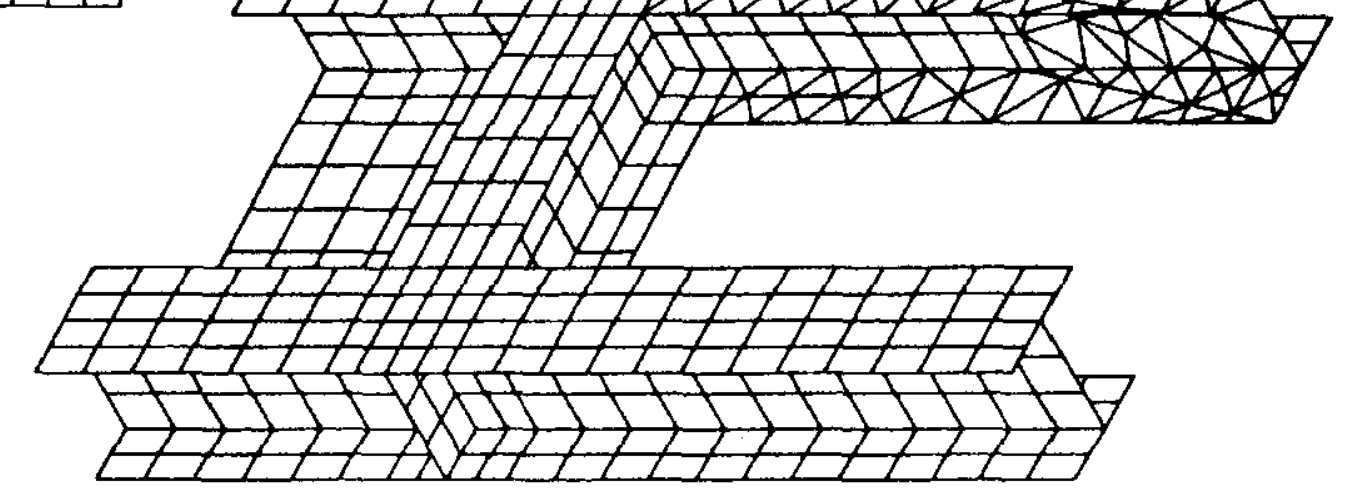

test lac module platform 


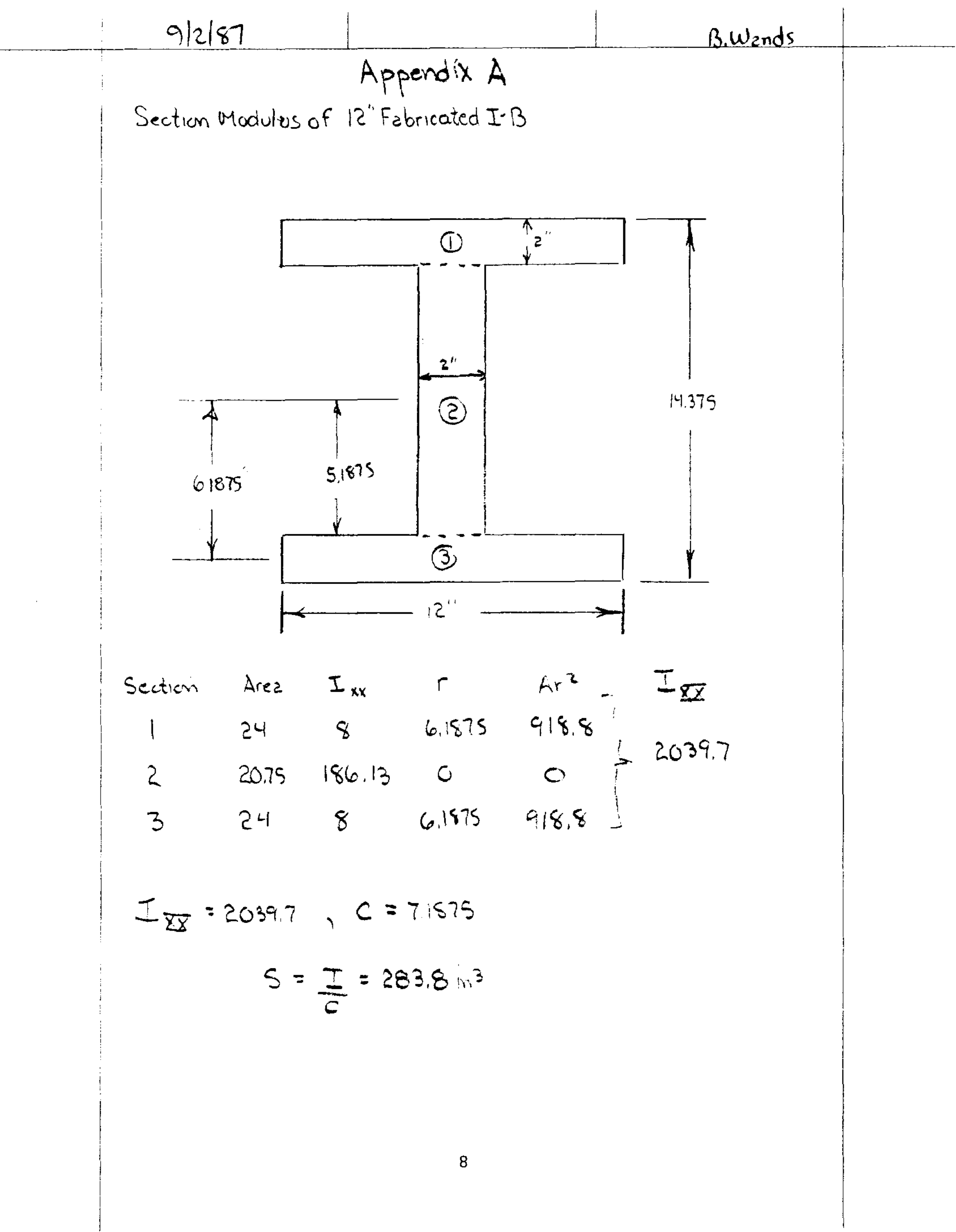

